\title{
Preterm Birth and Subsequent Risk of Acute Childhood Leukemia: a Meta- Analysis of Observational Studies
}

\author{
Qi-tao Huang $^{\mathrm{a}}$ Yun-fei Gao Mei Zhong $^{\mathrm{a}}$ Yan-hong Yu \\ aDivision of Obstetrics And Gynecology, Nanfang Hospital, Southern Medical University, Guangzhou, \\ China
}

\author{
Key Words \\ Preterm • Childhood • Leukemia
}

\begin{abstract}
Background: Preterm birth (PTB) has been recognized as a crucial long term risk factor for multiple non-communicable diseases. However, studies between the relationship of PTB and the risk of acute childhood leukemia have yielded inconclusive results. Therefore, we performed a meta-analysis to systematically review the current literature to investigate whether PTB is associated with increased risk of acute childhood leukemia. Methods: Three electronic databases (PubMed, Web of Science, and EMBASE) were searched up to December 1st, 2015. Relevant studies reporting the association between PTB and subsequent risk of acute childhood leukemia were included for further evaluation. Statistical analysis was performed using Revmen 5.3 and Stata 10.0. Results: A total of 12 studies for acute childhood leukemia, eight studies for acute lymphoblastic leukemia (ALL), and seven studies for acute myeloid leukemia (AML) were included in the current meta-analyses. We calculated pooled odds ratio (OR) and 95\% confidence interval (CI) to evaluate the relationship between PTB and acute childhood leukemia as well as its two subtypes: ALL and AML. Our results suggested that PTB was significantly associated with increased risk of acute childhood leukemia (OR $=1.09,95 \%$ $\mathrm{CI}=1.02-1.17, \mathrm{P}=0.01)$ and $\mathrm{AML}(\mathrm{OR}=1.42,95 \% \mathrm{CI}=1.21-1.67, \mathrm{P}<0.01)$. However, $\mathrm{PTB}$ was not significantly associated with an increased risk of $A L L(O R=1.04,95 \% C I=0.96-1.13, P$ $=0.29$ ). Conclusion: Our data showed that PTB increased the risk of AML. Further studies are required to explore causality and dissect the biological mechanisms involved.
\end{abstract}

\section{Introduction}

Preterm birth is a leading global health issue and is also the most common cause of neonatal morbidity and mortality [1]. Advances in neonatal care technologies, including implication of antenatal corticosteroids, surfactant therapy, as well as high frequency ventilation, have enabled unprecedented numbers of preterm infants to survive [2]. Currently, low gestational age at birth has been recognized as a crucial long term risk factor 
for multiple non-communicable diseases. A growing body of evidence has demonstrated that preterm birth infants are at a higher risk of developing diabetes, cardiovascular disease, respiratory disease, and neurological and psychiatric disorders in their adult life [3-7].

Acute leukemia is the most common cancer in children, but the causes in the majority of cases are not completely understood $[8,9]$. The influence of early life exposures on subsequent childhood malignancies is increasingly recognized, since mounting evidence suggests that a variety of perinatal factors such as prenatal parental smoking as well as high birth weight may elevate the incidence of childhood leukemia [10, 11]. Given the increasing survival rate of preterm birth infants and the restricted scope for prevention, preterm birth is becoming a more common early life exposures.

Although the associations between preterm birth and other non-communicable diseases are well established, studies on the relationship between preterm birth and the risk of acute childhood leukemia have yielded inconclusive results [12-24]. For instance, several studies suggested higher prevalence of acute leukemia in children born preterm when compared with their controls $[12,14,17,23,24]$, while other reports failed to demonstrate a positive association between preterm birth and increased risk of acute childhood leukemia $[13,15,16,18-22]$. This discrepancy might be due to the relatively small sample size for each individual study. As the association between preterm birth and the risk of acute childhood leukemia is far from clear, we performed a meta-analysis to systematically review the current literature to investigate whether preterm birth is associated with increased risk of acute childhood leukemia.

\section{Materials and Methods}

This systematic review and meta-analysis was performed following the guidance provided in the Cochrane Handbook and was reported according to the Meta-analysis of Observational Studies in Epidemiology (MOOSE) guidelines [25].

\section{Data sources and search strategy}

Three electronic databases (PubMed, Web of Science, and EMBASE) were searched up to December 1st, 2015 using combinations of the following terms: "preterm" or "risk factor" or "birth weight" and "acute lymphoblastic leukemia" or "acute myeloid leukemia" or "tumor" or "cancer" or "carcinoma" and "child" or "children" or "childhood". We sifted through potentially relevant articles first by titles and abstracts and then we retrieved full texts for detailed review. Further, we scanned the reference lists of articles that met the inclusion criteria in our analysis, and searched for those articles or citations in Google Scholar and Google to obtain additional studies.

\section{Inclusion and exclusion criteria}

We considered any case-control, cross-section or cohortstudies that examined the association between preterm birth and acute childhood leukemia as well as its two subtypes: acute lymphoblastic leukemia (ALL) and/or acute myeloid leukemia (AML). Studies were excluded if (i) there was no control group; (ii) there was no matched or unmatched unexposed cohort; (iii) incidence of leukemia was not reported. In addition, case reports and case series were excluded. PTB diagnosis was defined as delivery before 37 weeks of gestation. No language restrictions were used for study inclusion in this meta-analysis.

\section{Data extraction}

Two independent investigators performed the data extraction. The following information was recorded: first author's last name, year of publication and country of origin, age distribution of the study population, number of cases and study population, and adjustments for confounding factors (Table 1).

Assessment of methodological quality

Two independent investigators evaluated the quality of each study using the Newcastle-Ottawa Quality Assessment Scale (NOS), a validated modality for assessing observational and non-randomized studies [26]. The scale uses a scoring system based on three major criteria: selection of participants, comparability 


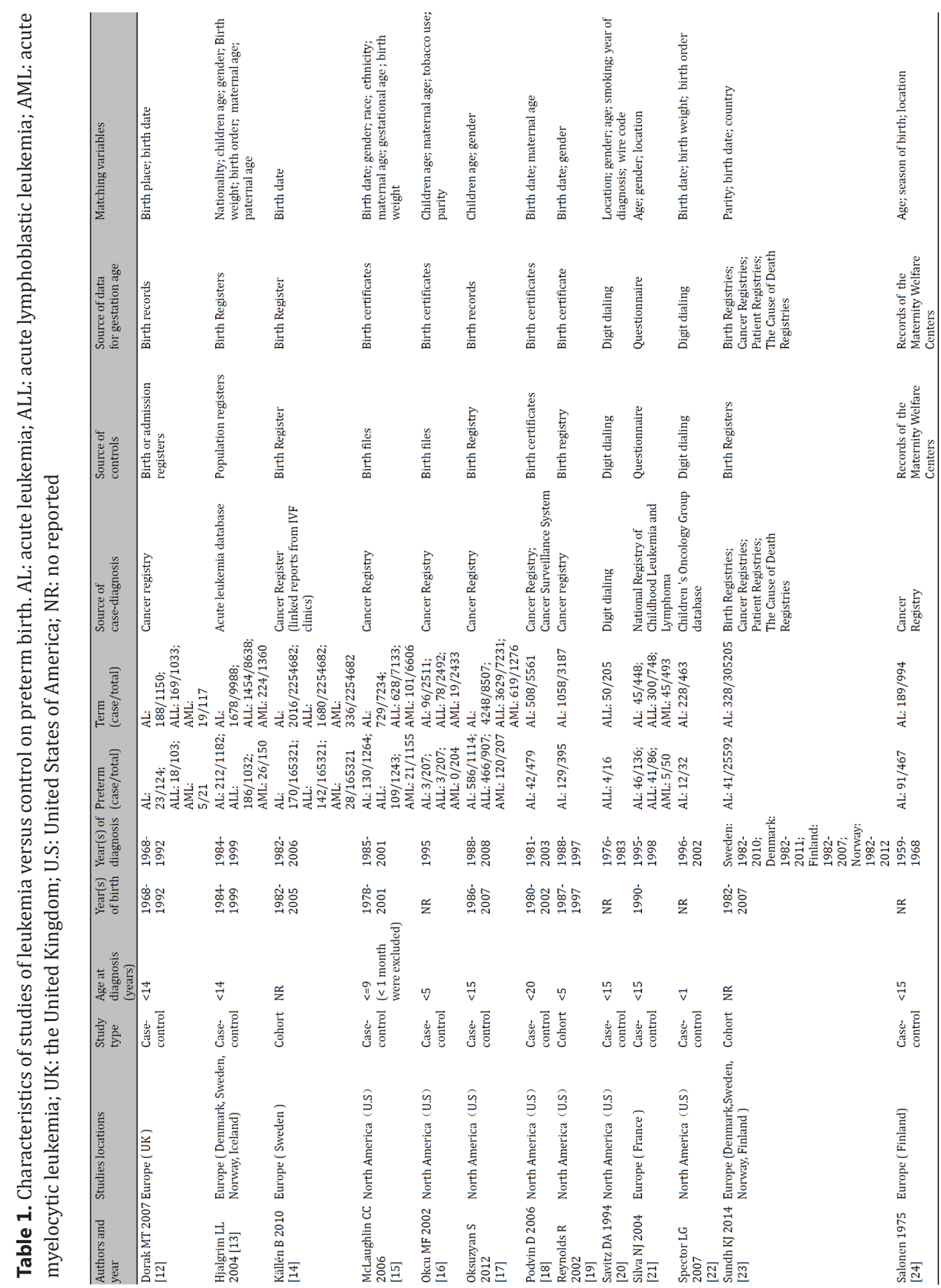

of study groups, and assessment of exposure. The quality checklist includes eight items with a score of either 0 or 1 for each item except 'comparability of cohorts' where a score of 0,1 or 2 can be awarded. Therefore, the quantitative appraisal of overall quality of the individual studies ranged from 0 to 9 . In our analysis, studies of low, intermediate and high quality were defined with NOS scores of 1-3, 4-6, and 7-9, respectively. Studies of low quality were set for exclusion in the meta-analysis. 
Assessment of heterogeneity and statistical analysis

Pooled odds ratios (OR) with 95\% confidence intervals (CIs) between preterm birth and acute childhood leukemia, ALL, as well as AML were used to estimate effect sizes. We assessed whether eligible studies had sufficient similarity in their design and clinical characteristics to ensure that pooling was valid. Statistical heterogeneity in the results of the studies was assessed by using Cochran $Q$ and $\mathrm{I}^{2}$ tests [27]. $\mathrm{P}<0.10$ for the $\mathrm{Q}$ test or $\mathrm{I}^{2}>50 \%$ were considered as statistically significant heterogeneity. The OR were combined in a meta-analysis using a fixed-effects model when heterogeneity observed among studies was absent to moderate, or for a random-effects model, when heterogeneity was significant. The publication bias was investigated by two methods. Visual detection was used to analyze the funnel plots. Quantitative analysis was performed by the Begg's and Egger's regression asymmetry test [28]. Statistical analysis was performed using Revmen 5.3 and Stata 10.0 .

\section{Results}

\section{Characteristics of the Subjects in the Selected Studies}

Detailed search procedures are summarized in Figure 1. The full text of the 29 identified articles was retrieved for detailed evaluation. Seventeen of these articles were further excluded because they did not meet the inclusion criteria: four studies were reviews or commentaries, five studies did not contain preterm birth data and eight studies did not contain leukemia data. Finally, the remaining 12 independent studies were used in the current analysis (Table 1).

\section{Main Analysis}

A total of 12 studies including 2,786,687 participants and 13,319 cases were selected in this meta-analysis of acute childhood leukemia [12-23]. The results suggested that preterm birth was significantly associated with an increased risk of acute childhood leukemia when

Fig. 1. Flow chart of the literature search and selection.

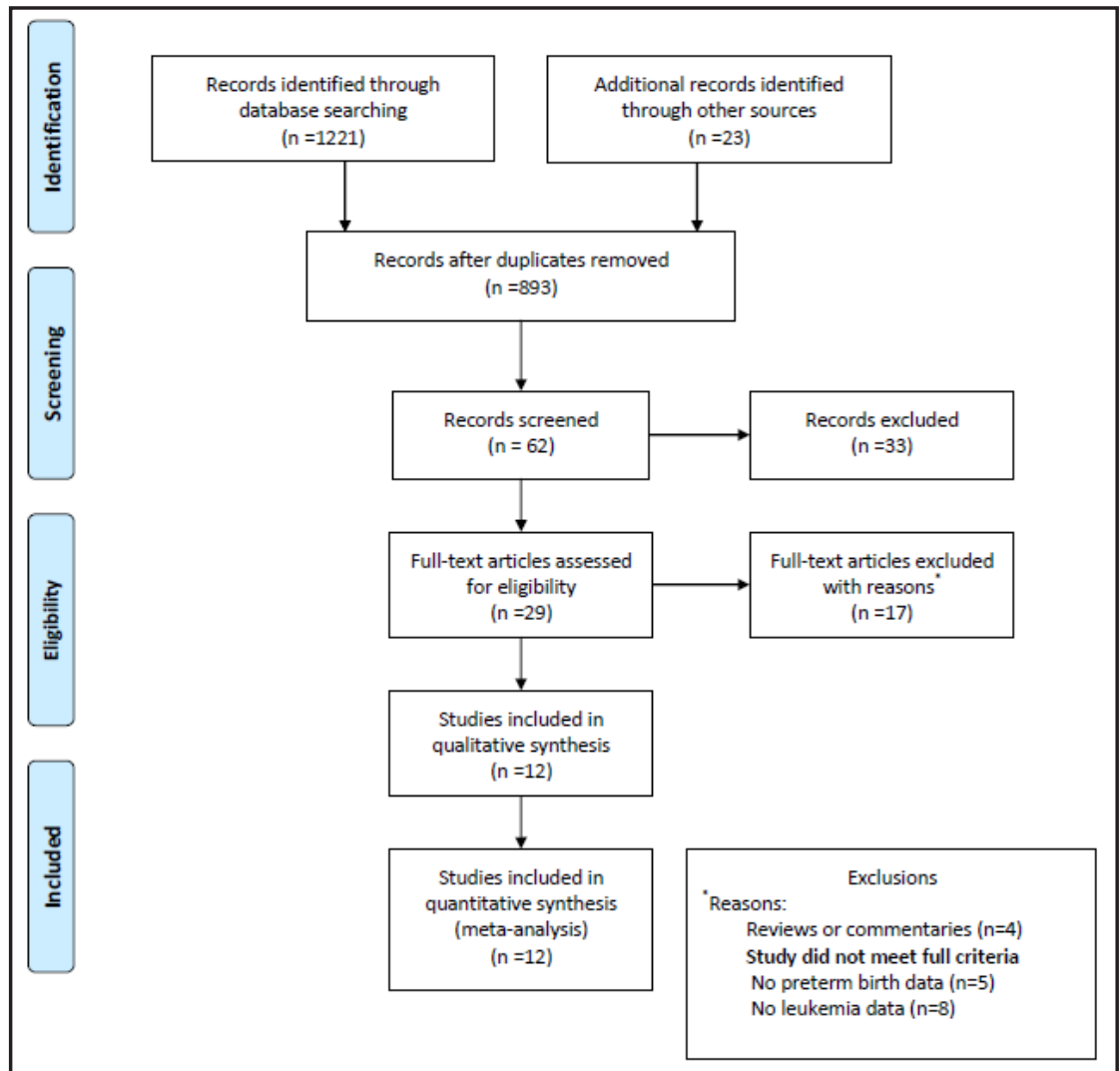




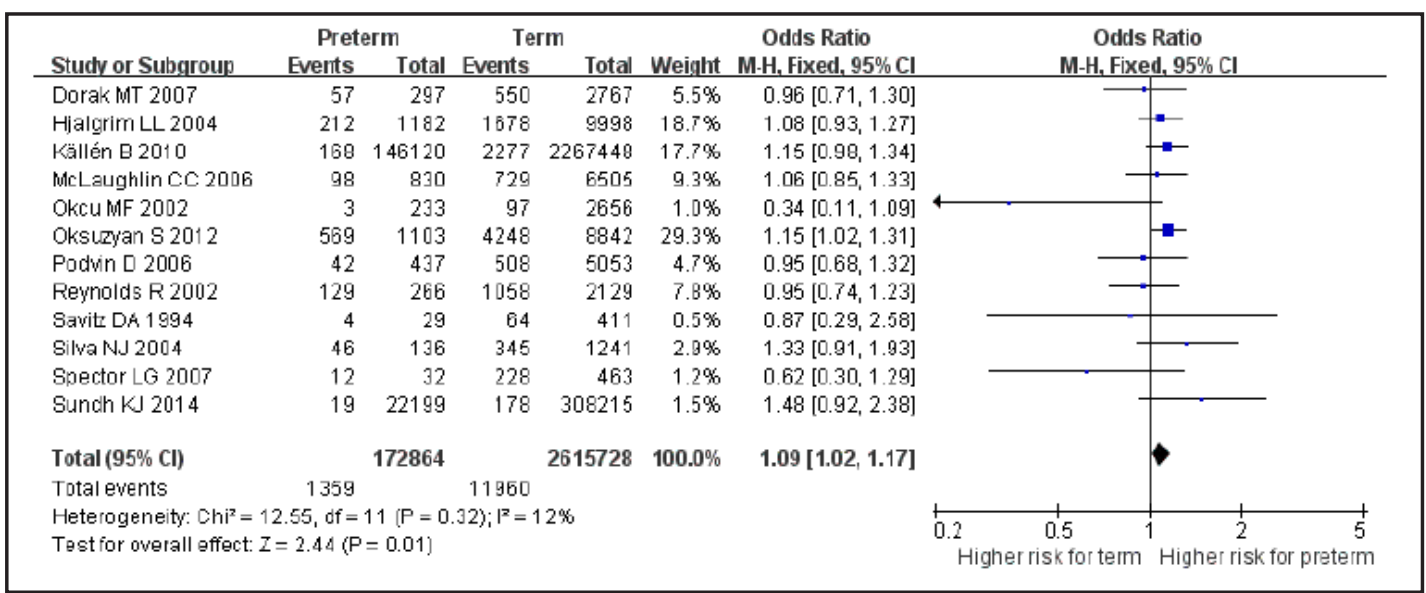

Fig. 2. Forest plot of the association between preterm birth and risk of acute childhood leukemia.

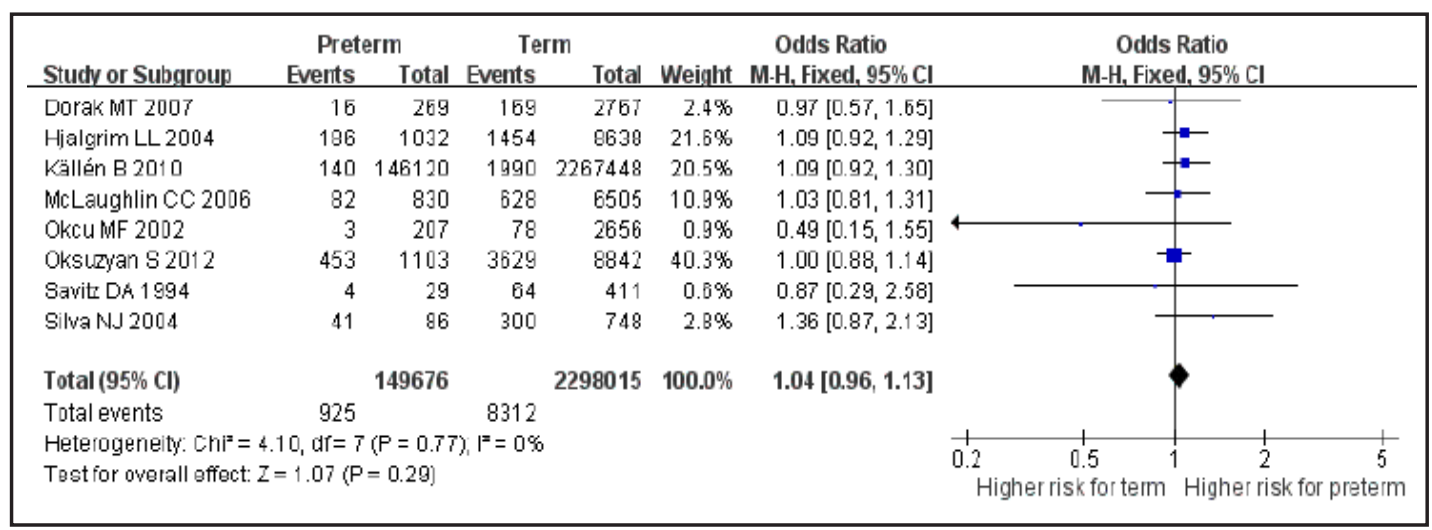

Fig. 3. Forest plot of the association between preterm birth and risk of acute childhood lymphoblastic leukemia.

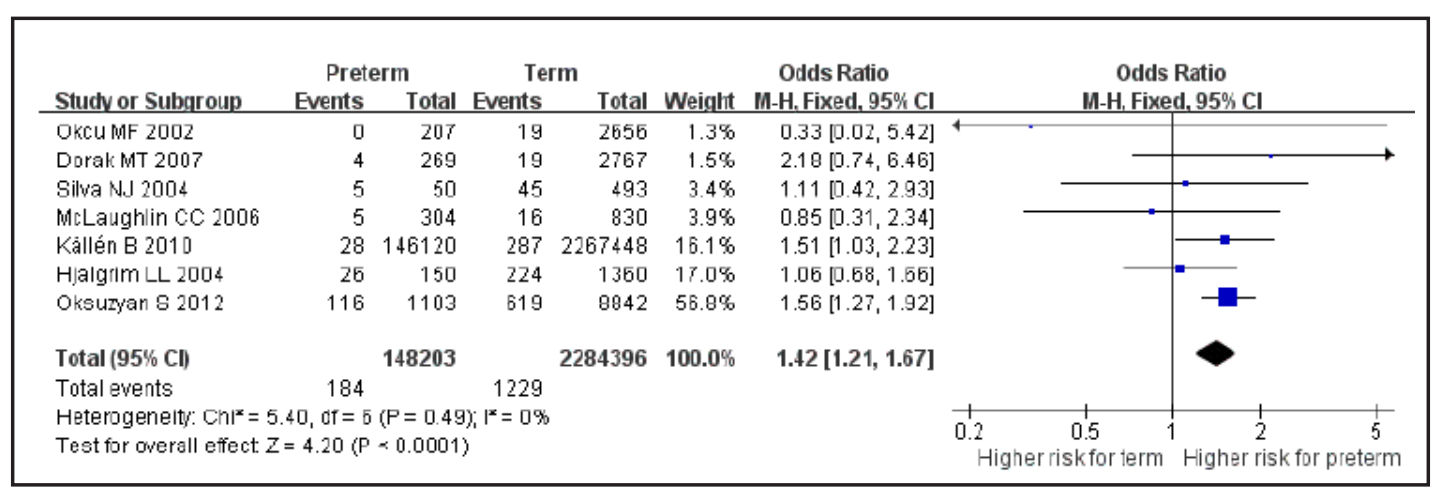

Fig. 4. Forest plot of the association between preterm birth and risk of acute childhood myeloid leukemia.

compared to full-term birth $(\mathrm{OR}=1.09,95 \% \mathrm{CI}=1.02-1.17)$, with mild heterogeneity $\left(\mathrm{I}^{2}=\right.$ $12.0 \%, P=0.33$ ) (Fig. 2).

Eight studies including 2,447,691 participants and 9,237 cases were selected in this meta-analysis of childhood ALL [12-17, 20, 21]. The results suggested that preterm birth was not significantly associated with increased risk of ALL when compared to full-term birth $(\mathrm{OR}=1.04,95 \% \mathrm{CI}=0.96-1.13)$, with no heterogeneity $\left(\mathrm{I}^{2}=0.0 \%, \mathrm{P}=0.77\right)$ (Fig. 3$)$.

Seven studies including 2,432,599 participants and 1,413 cases were selected in this meta-analysis of childhood AML $[12-17,21]$. The results suggested that preterm birth was 


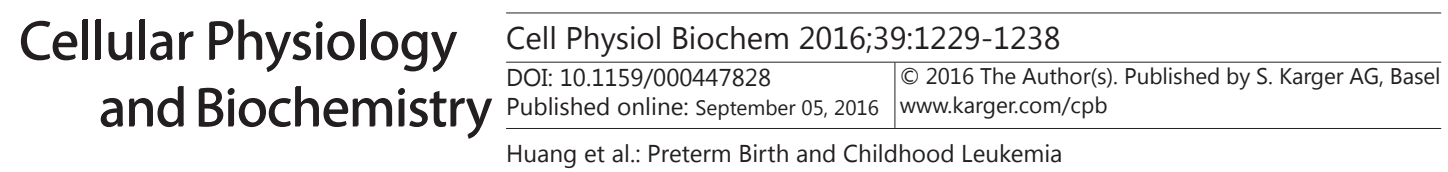

Table 2. Subgroup analysis of the association between preterm birth and childhood leukemia. AL: acute leukemia; ALL: acute lymphoblastic leukemia; AML: acute myeloid leukemia. Bold figures indicated $\mathrm{P}<0.05$

\begin{tabular}{|c|c|c|c|c|c|c|c|c|}
\hline \multirow{3}{*}{$\overline{\text { Study type }}$} & \multirow{2}{*}{\multicolumn{2}{|c|}{$\begin{array}{c}\text { AL } \\
\text { Studies OR(95\%Cl) }\end{array}$}} & \multirow[b]{2}{*}{$I^{2}$} & \multicolumn{2}{|c|}{ ALL } & \multicolumn{2}{|r|}{ AML } & \multirow[b]{2}{*}{$I^{2}$} \\
\hline & & & & \multicolumn{2}{|c|}{ Studies $\mathrm{OR}(95 \% \mathrm{Cl})$} & $I^{2}$ Studies $\mathrm{OB}(95 \% \mathrm{Cl}$ & Studies OR(95\%CI) & \\
\hline & & & & & & & & \\
\hline Cohort & 3 & $1.15(0.95-1.40$ & ) $56 \%$ & & $1.15(0.97-1.37)$ & ) -1 & $1.14[0.77-1$ & \\
\hline Case-control & 10 & $1.07(0.99-1.15$ & $0 \%$ & 7 & $1.05(0.96-1.15)$ & $0 \% 6$ & $1.28(1.04-1$ & 7) $0 \%$ \\
\hline \multicolumn{9}{|l|}{ Countries } \\
\hline Europe & 6 & $1.14(1.04-1.26)$ & 5) $0 \%$ & 4 & $1.13(1.01-1.27)$ & $0 \% 4$ & $1.13(0.86-1$ & 8) $0 \%$ \\
\hline North America & 7 & $1.04(0.95-1.13$ & 3) $11 \%$ & & $1.02(0.91-1.14)$ & $0 \% 3$ & $1.35(1.06-1$ & 4) $0 \%$ \\
\hline \multicolumn{9}{|l|}{ Children gender } \\
\hline Matched & 5 & $1.09(1.00-1.19$ & $0 \%$ & 4 & $1.08(0.97-1.19]$ & $0 \% 3$ & $1.32(1.04-1$ & 7) $0 \%$ \\
\hline Higher in $b$ & 6 & $1.05(0.93-1.20$ & $39 \%$ & & $0.98(0.80-1.18)$ & $0 \% 3$ & $1.17[0.76-1$ & 9) $0 \%$ \\
\hline Higher in girl & 1 & $0.62(0.30-1.29$ & & 0 & - & & - & - \\
\hline undefined & 1 & $1.15(0.98-1.35$ & & 1 & $1.15(0.97-1,37)$ & ) -1 & $1.14(0.77-1$ & \\
\hline \multicolumn{9}{|l|}{ Mean age of leukemia diagnosis } \\
\hline$<5$ years & 8 & $1.05(0.97-1.15$ & 5) $17 \%$ & & $1.04(0.93-1.16)$ & $0 \% 5$ & $1.35(1.07-1$ & $0 \%$ \\
\hline undefined & 5 & $1.13(1.02-1.25$ & 5) $0 \%$ & 3 & $1.12(0.99-1.26)$ & $0 \% 2$ & $1.10[0.82-1$ & $8 \%$ \\
\hline \multicolumn{9}{|l|}{ Source of data for gestation age } \\
\hline Register or record & 10 & $1.07(1.00-1.15$ & 5) $0 \%$ & 6 & $1.07(0.98-1.16)$ & $0 \% 6$ & $1.25[1.04-1$ & 1) $0 \%$ \\
\hline Digit dialing or questionnaire & 3 & $1.11(0.81-1.54$ & & & $1.31(0.87-1.99)$ & $0 \% 1$ & $1.11(0.42-2$ & \\
\hline
\end{tabular}

significantly associated with increased risk of AML when compared to full-term birth (OR = $1.42,95 \% \mathrm{CI}=1.21-1.67)$, with no heterogeneity $\left(\mathrm{I}^{2}=0.0 \%, \mathrm{P}=0.49\right)$ (Fig. 4).

\section{Subgroup Analysis}

A subgroup analysis of the results according to study type (AL: cohort [14, 19, 23] or case-control [12-18, 20-22, 24]; ALL: cohort [14] or case-control [12, 13, 15-17, 20, 21]; AML: cohort [14] or case-control [12,13,15,16,17,21]), children's gender (AL: matched [13, $17,19-21]$, higher in boy $[12,15,16,18,23,24]$, Higher in girl [22], or undefined [14]; ALL: matched $[12,17,20,21]$, higher in boy $[12,15,16]$, higher in girl (none), or undefined [14]; AML: matched $[13,17,21]$, higher in boy $[12,15,16]$, higher in girl (none), or undefined [14]), children's age of leukemia diagnosis (AL: $<5$ years old $[12,15-22]$ or undefined $[13,14$, $20,23,24]$;ALL: $<5$ years old $[12,15-17,21]$ or undefined $[13,14,20]$; AML: $<5$ years old $[12$, $15-17,21]$ or undefined $[13,14])$ and source of data for gestation age (AL: register or record $[12-19,23,24]$ or digit dialing or questionnaire [1, 2, 4-7, 9-11, 13]; ALL: register or record [12-17] or digit dialing or questionnaire [20, 21]; AML: register or record [12-17] or digit dialing or questionnaire [21]) is summarized inTable 2.

Subgroup analysis with respect to children's age of leukemia diagnosis demonstrated that children born preterm under 5 years old had the highest risk of developing AML (OR $1.35,95 \%$ CI 1.07-1.70) , while such associations were not significant in AL as well as ALL.

\section{Publication bias}

There was no evidence of publication bias for acute childhood leukemia (Begg's test: $\mathrm{P}=$ 0.246; Egger's test: $P=0.269$ ), childhood ALL (Begg's test: $P=0.711$;Egger's test: $P=0.602$ ) as well as childhood AML (Begg's test: $\mathrm{P}=0.548$; Egger's test: $\mathrm{P}=0.238$ ).

\section{Discussion}

While children born preterm were associated with increased incidence of diabetes, cardiovascular disease, respiratory disease, and neurological and psychiatric disorders in their adulthood life [3-7], one intriguing observation was about the prevalence of the childhood leukemia. Given the increasing number of children surviving preterm birth [29], any potential causal association between preterm birth and childhood leukemia could have a profound impact on public health issues. Our meta-analysis demonstrated that children 


\section{Cellular Physiology Cell Physiol Biochem 2016;39:1229-1238 \\ and BiOChemistry \begin{tabular}{l|l} 
DOI: $10.1159 / 000447828$ & Published online: September 05, 2016 \\
www.karger.com/cpb
\end{tabular} \\ Huang et al.: Preterm Birth and Childhood Leukemia}

born preterm were significantly associated with increased risk of acute leukemia. Moreover, our sub-group analysis further confirmed the positive relationship between preterm birth and AML, while no significant association was observed between children born preterm and their subsequent incidence of ALL.

There are several potential biologic explanations for the association between preterm birth and childhood AML. First, childhood leukemia is a cancer of the immune system. Therefore, abnormal immunity development or dysfunction of the immune system during childhood may play a crucial role in the pathogenesis of leukemia [30, 31]. Currently, mounting evidence has demonstrated that children born preterm also have increased incidence of other immune-related diseases such as allergy, asthma, and type 1 diabetes $[3,32,33]$. Secondly, a previous meta-analysis study evaluated the associations between leukemia and its subtypes (ALL and AML) with high birth weight [10]. Their observed results demonstrated that high birth weight was associated with increased risk of overall leukemia and ALL as well as AML. The hypothesis of the association between high birth weight and increased incidence of leukemia was based on two pieces of evidence: 1) significantly positive associations observed between insulin-like growth factors (IGFs) and many aspects of fetal growth; 2) the important role of IGFs in carcinogenesis [10, 34-40]. A previous experimental study demonstrated that IGF-1stimulation could promote the growth of lymphoid and myeloid cells [41]. Furthermore, over-expression of IGF-2 was associated with increased incidence of AML and ALL $[42,43]$. Although premature infants may not experience overstimulation of IGF in utero, the postnatal catch-up growth resulting from growth failure during early life may lead to later over-exposure of IGF $[44,45]$. A previous study seemed to support our hypothesis by demonstrating a significantly greater urinary output of IGF-2 in infants born preterm than those of full-term and suggested this may reflect a period of persistent IGF-2 elevation due to the catch-up growth of these infants [46]. Several recent studies also suggested serum IGF-1 level is closely related to early accelerated growth in preterm children $[47,48]$. Moreover, one previous publication found preterm children even around 9 years old had higher IGF-1 concentrations than their term controls [49].

Preterm infants were born into an adverse environment from the very moment their first breath were taken. For instance, respiratory distress in preterm infants were often treated with supplemental oxygen. Several recent studies demonstrated that hyperoxic exposure of immature mice would increase the inflammatory response to subsequent viral infection and lead to persistent alterations in natural killer cells function [50,51], which played an important role in maintaining homeostasis in peripheral tissues. In addition, preterm infants were often growth-restricted. Feeding them with calorie and protein-enriched formula milk might facilitate "catch-up" growth and improve development [52]. However, the preterm gut was very sensitive to enteral feeding. Growing evidence indicated that enteral feeding with formula may induce subclinical inflammation in the premature intestine and may increase the susceptibility for the immune system dysfunction [53]. Therefore, to further explore the association between the "toxic" environment of neonatal intensive care unit's in terms of the very therapies necessary to sustain this fragile population and later adverse outcomes such as metabolic syndrome and altered immune status, will assist future research endeavours that may lead to practice changes.

To the best of our knowledge, this is the first comprehensive systematic review of the association between preterm birth and the risk of childhood leukemia. Our meta-analysis has some strengths. Firstly, both case-control and cohort studies were included to explore the relationships between preterm birth and acute childhood leukemia and its major subtypes. Secondly, a large number of participants and cases guaranteed the sufficient statistical power to achieve reliable conclusions. Thirdly, our findings provided a good estimation of the association between preterm birth and the risk of childhood leukemia, since no publication bias was observed and the heterogeneity was low among included studies. Finally, our findings could avoid the recall bias, since subgroup analysis of all the studies measured gestation age by registry or records also demonstrated significant association between preterm birth and increased risk of acute childhood leukemia as well as its subtype AML. 


\section{Cellular Physiology Cell Physiol Biochem 2016;39:1229-1238 \begin{tabular}{l|l|l}
\hline DOI: 10.1159/000447828 & $\begin{array}{l}\text { C) 2016 The Author(s). Published by S. Karger AG, Basel } \\
\text { www.karger.com/cpb }\end{array}$
\end{tabular} \\ Huang et al.: Preterm Birth and Childhood Leukemia}

However, several limitations should be also addressed. Firstly, the included studies were mainly performed in America and Europe. Therefore, our findings might not be suitablyapplied to other populations. Secondly, though the majority of included studies adjusted for the most important confounders, those adjustments were very different across different studies, which might influence the results of this meta-analysis. Thirdly, although our results suggested that children born preterm under 5 years old had the highest risk of developing AML, age differences among the studies of children with acute leukemia were relatively large. For instance, some studies included cases from 0 to 16 years old without detailed information. Therefore, we were unable to conduct a more precise analysis to assess the relationship between preterm birth and the risk of leukemia at specific age ranges. Finally, only few studies recorded the incidence of childhood leukemia in infants born extremely preterm $(<28$ gestational weeks). Future studies could aim to confirm whether earlier gestational age is associated with increased risk of childhood leukemia.

In conclusion, our meta-analysis indicated that preterm birth is a significant risk factor for acute childhood leukemia, particularly for AML. Our findings highlight that effective interventions are urgently needed to prevent preterm birth. Additionally, more research is required to clarify the underlying mechanisms of preterm birth in the development of these multiple non-communicable diseases, in consideration of the global increase in the survival of children born preterm due to improved medical care. Moreover, research focused on the relationship between preterm birth and other types of childhood malignancies may be needed in the near future.

\section{Acknowledgments}

The authors thank Dr Oksana Shynlova from Lunenfeld-Tanenbaum Research Institute, Mount Sinai Hospital, Toronto, Ontario, Canada for reviewing the manuscript. This work was supported by the National Natural Science Foundation of China (81401208) , Natural Science Foundation of Guangdong Province(2015A030310025) and the President Grant from Nanfang Hospital (2012C026, 2014B003).

\section{Disclosure Statement}

The authors have no competing interests to declare.

\section{Reference}

1 Blencowe H, Cousens S, Oestergaard MZ, Chou D, Moller AB, Narwal R, Adler A, Vera GC, Rohde S, Say L, Lawn JE: National, regional, and worldwide estimates of preterm birth rates in the year 2010 with time trends since 1990 for selected countries: A systematic analysis and implications. Lancet 2012;379:21622172.

2 Crump C: Medical history taking in adults should include questions about preterm birth. BMJ 2014;349:g4860.

3 Li S, Zhang M, Tian H, Liu Z, Yin X, Xi B: Preterm birth and risk of type 1 and type 2 diabetes: Systematic review and meta-analysis. Obes Rev 2014;15:804-811.

4 Li S, Xi B: Preterm birth is associated with risk of essential hypertension in later life. Int J Cardiol 2014;172:e361-e363.

5 Parkinson JR, Hyde MJ, Gale C, Santhakumaran S, Modi N: Preterm birth and the metabolic syndrome in adult life: A systematic review and meta-analysis. Pediatrics 2013;131:e1240-e1263.

6 Been JV, Lugtenberg MJ, Smets E, van Schayck CP, Kramer BW, Mommers M, Sheikh A: Preterm birth and childhood wheezing disorders: A systematic review and meta-analysis. PLoS Med 2014;11:e1001596.

7 Burnett AC, Anderson PJ, Cheong J, Doyle LW, Davey CG, Wood SJ: Prevalence of psychiatric diagnoses in preterm and full-term children, adolescents and young adults: A meta-analysis. Psychol Med 2011;41:2463-2474. 


\section{Cellular Physiology Cell Physiol Biochem 2016;39:1229-1238

 \\ Huang et al.: Preterm Birth and Childhood Leukemia}

8 Puumala SE, Ross JA, Aplenc R, Spector LG: Epidemiology of childhood acute myeloid leukemia. Pediatr Blood Cancer 2013;60:728-733.

9 Wiemels J: Perspectives on the causes of childhood leukemia. Chem Biol Interact 2012;196:59-67.

10 Caughey RW, Michels KB: Birth weight and childhood leukemia: A meta-analysis and review of the current evidence. Int J Cancer 2009;124:2658-2670.

11 Milne E, Greenop KR, Scott RJ, Bailey HD, Attia J, Dalla-Pozza L, de Klerk NH, Armstrong BK: Parental prenatal smoking and risk of childhood acute lymphoblastic leukemia. Am J Epidemiol 2012;175:43-53.

12 Dorak MT, Pearce MS, Hammal DM, McNally RJ, Parker L: Examination of gender effect in birth weight and miscarriage associations with childhood cancer (United Kingdom). Cancer Causes Control 2007;18:219228.

13 Hjalgrim LL, Rostgaard K, Hjalgrim H, Westergaard T, Thomassen H, Forestier E, Gustafsson G, Kristinsson J, Melbye M, Schmiegelow K: Birth weight and risk for childhood leukemia in Denmark, Sweden, Norway, and Iceland. J Natl Cancer Inst 2004;96:1549-1556.

14 Kallen B, Finnstrom O, Lindam A, Nilsson E, Nygren KG, Olausson PO: Cancer risk in children and young adults conceived by in vitro fertilization. Pediatrics 2010;126:270-276.

15 McLaughlin CC, Baptiste MS, Schymura MJ, Nasca PC, Zdeb MS: Birth weight, maternal weight and childhood leukaemia. Br J Cancer 2006;94:1738-1744.

16 Okcu MF, Goodman KJ, Carozza SE, Weiss NS, Burau KD, Bleyer WA, Cooper SP: Birth weight, ethnicity, and occurrence of cancer in children: A population-based, incident case-control study in the State of Texas, USA. Cancer Causes Control 2002;13:595-602.

17 Oksuzyan S, Crespi CM, Cockburn M, Mezei G, Kheifets L: Birth weight and other perinatal characteristics and childhood leukemia in California. Cancer Epidemiol 2012;36:e359-e365.

18 Podvin D, Kuehn CM, Mueller BA, Williams M: Maternal and birth characteristics in relation to childhood leukaemia. Paediatr Perinat Epidemiol 2006;20:312-322.

19 Reynolds P, Von Behren J, Elkin EP: Birth characteristics and leukemia in young children. Am J Epidemiol 2002;155:603-613.

20 Savitz DA, Ananth CV: Birth characteristics of childhood cancer cases, controls, and their siblings. Pediatr Hematol Oncol 1994;11:587-599.

21 Jourdan-Da SN, Perel Y, Mechinaud F, Plouvier E, Gandemer V, Lutz P, Vannier JP, Lamagnere JL, Margueritte G, Boutard P, Robert A, Armari C, Munzer M, Millot F, De Lumley L, Berthou C, Rialland X, Pautard B, Hemon D, Clavel J: Infectious diseases in the first year of life, perinatal characteristics and childhood acute leukaemia. Br J Cancer 2004;90:139-145.

22 Spector LG, Davies SM, Robison LL, Hilden JM, Roesler M, Ross JA: Birth characteristics, maternal reproductive history, and the risk of infant leukemia: A report from the Children's Oncology Group. Cancer Epidemiol Biomarkers Prev 2007;16:128-134.

23 Sundh KJ, Henningsen AK, Kallen K, Bergh C, Romundstad LB, Gissler M, Pinborg A, Skjaerven R, Tiitinen A, Vassard D, Lannering B, Wennerholm UB: Cancer in children and young adults born after assisted reproductive technology: A Nordic cohort study from the Committee of Nordic ART and Safety (CoNARTaS). Hum Reprod 2014;29:2050-2057.

24 Salonen T, Saxen L: Risk indicators in childhood malignancies. Int J Cancer 1975;15:941-946.

25 Stroup DF, Berlin JA, Morton SC, Olkin I, Williamson GD, Rennie D, Moher D, Becker BJ, Sipe TA, Thacker SB: Meta-analysis of observational studies in epidemiology: A proposal for reporting. Meta-analysis of Observational Studies in Epidemiology (MOOSE) group. JAMA 2000;283:2008-2012.

26 Wells G, Shea BO, Connell D :The Newcastle-Ottawa Scale (Nos) For Assessing The Quality Of Nonrandomized Studies In Meta-Analysis, 2010 http://www.ohri.ca/programs/clinical_epidemiology/ oxford_web.ppt.

27 Higgins JP, Thompson SG, Deeks JJ, Altman DG: Measuring inconsistency in meta-analyses. BMJ 2003;327:557-560.

28 Egger M, Smith GD: Bias in location and selection of studies. BMJ 1998;316:61-66.

29 Morken NH: Preterm birth: New data on a global health priority. Lancet 2012;379:2128-2130.

30 Lion E, Willemen Y, Berneman ZN, Van Tendeloo VF, Smits EL: Natural killer cell immune escape in acute myeloid leukemia. Leukemia 2012;26:2019-2026.

31 Campos-Sanchez E, Toboso-Navasa A, Romero-Camarero I, Barajas-Diego M, Sanchez-Garcia I, Cobaleda C: Acute lymphoblastic leukemia and developmental biology: A crucial interrelationship. Cell Cycle 2011;10:3473-3486. 


\section{Cellular Physiology Cell Physiol Biochem 2016;39:1229-1238 \begin{tabular}{l|l|l|l|} 
DOI: 10.1159/000447828 & $\begin{array}{l}\text { (c) 2016 The Author(s). Published by S. Karger AG, Basel } \\
\text { www.karger.com/cpb }\end{array}$
\end{tabular} \\ Huang et al.: Preterm Birth and Childhood Leukemia}

32 Jaakkola JJ, Ahmed P, Ieromnimon A, Goepfert P, Laiou E, Quansah R, Jaakkola MS: Preterm delivery and asthma: A systematic review and meta-analysis. J Allergy Clin Immunol 2006;118:823-830.

33 Buske-Kirschbaum A, Krieger S, Wilkes C, Rauh W, Weiss S, Hellhammer DH: Hypothalamic-pituitaryadrenal axis function and the cellular immune response in former preterm children. J Clin Endocrinol Metab 2007;92:3429-3435.

34 Milne E, Greenop KR, Metayer C, Schuz J, Petridou E, Pombo-de-Oliveira MS, Infante-Rivard C, Roman E, Dockerty JD, Spector LG, Koifman S, Orsi L, Rudant J, Dessypris N, Simpson J, Lightfoot T, Kaatsch P, Baka M, Faro A, Armstrong BK, Clavel J, Buffler PA: Fetal growth and childhood acute lymphoblastic leukemia: Findings from the childhood leukemia international consortium. Int J Cancer 2013;133:2968-2979.

35 Papadopoulou C, Antonopoulos CN, Sergentanis TN, Panagopoulou P, Belechri M, Petridou ET: Is birth weight associated with childhood lymphoma? A meta-analysis. Int J Cancer 2012;130:179-189.

36 Harder T, Plagemann A, Harder A: Birth weight and subsequent risk of childhood primary brain tumors: A meta-analysis. Am J Epidemiol 2008;168:366-373.

37 Cao H, Wang G, Meng L, Shen H, Feng Z, Liu Q Du J: Association between circulating levels of IGF-1 and IGFBP-3 and lung cancer risk: A meta-analysis. PLoS One 2012;7:e49884.

38 Chen W, Wang S, Tian T, Bai J, Hu Z, Xu Y, Dong J, Chen F, Wang X, Shen H: Phenotypes and genotypes of insulin-like growth factor 1, IGF-binding protein-3 and cancer risk: Evidence from 96 studies. Eur J Hum Genet 2009;17:1668-1675.

39 Elhddad AS, Lashen H: Fetal growth in relation to maternal and fetal IGF-axes: A systematic review and meta-analysis. Acta Obstet Gynecol Scand 2013;92:997-1006.

40 Agrogiannis GD, Sifakis S, Patsouris ES, Konstantinidou AE: Insulin-like growth factors in embryonic and fetal growth and skeletal development (Review). Mol Med Rep 2014;10:579-584.

41 Alpdogan O, Muriglan SJ, Kappel BJ, Doubrovina E, Schmaltz C, Schiro R, Eng JM, Greenberg AS, Willis LM, Rotolo JA, O'Reilly RJ, van den Brink MR: Insulin-like growth factor-I enhances lymphoid and myeloid reconstitution after allogeneic bone marrow transplantation. Transplantation 2003;75:1977-1983.

42 Wu HK, Weksberg R, Minden MD, Squire JA: Loss of imprinting of human insulin-like growth factor II gene, IGF2, in acute myeloid leukemia. Biochem Biophys Res Commun 1997;231:466-472.

43 Vorwerk P, Wex H, Bessert C, Hohmann B, Schmidt U, Mittler U: Loss of imprinting of IGF-II gene in children with acute lymphoblastic leukemia. Leuk Res 2003;27:807-812.

44 Tinnion R, Gillone J, Cheetham T, Embleton N: Preterm birth and subsequent insulin sensitivity: A systematic review. Arch Dis Child 2014;99:362-368.

45 Hansen-Pupp I, Lofqvist C, Polberger S, Niklasson A, Fellman V, Hellstrom A, Ley D: Influence of insulinlike growth factor I and nutrition during phases of postnatal growth in very preterm infants. Pediatr Res 2011;69:448-453.

46 Quattrin T, Albini CH, Sportsman C, Shine BJ, MacGillivray MH: Urinary insulin-like growth factor-II excretion in healthy infants and children with normal and abnormal growth. Pediatr Res 1993;34:435-438.

47 van de Lagemaat M, Rotteveel J, Heijboer AC, Lafeber HN, van Weissenbruch MM: Growth in preterm infants until six months postterm: The role of insulin and IGF-I. Horm Res Paediatr 2013;80:92-99.

48 Hansen-Pupp I, Hovel H, Lofqvist C, Hellstrom-Westas L, Fellman V, Huppi PS, Hellstrom A, Ley D: Circulatory insulin-like growth factor-I and brain volumes in relation to neurodevelopmental outcome in very preterm infants. Pediatr Res 2013;74:564-569.

49 Kistner A, Deschmann E, Legnevall L, Vanpee M: Preterm born 9-year-olds have elevated IGF-1 and low prolactin, but levels vary with behavioural and eating disorders. Acta Paediatr 2014;103:1198-1205.

50 Reilly EC, Martin KC, Jin GB, Yee M, O'Reilly MA, Lawrence BP: Neonatal hyperoxia leads to persistent alterations in NK responses to influenza a virus infection. Am J Physiol Lung Cell Mol Physiol 2015;308:L76-L85.

51 Cui TX, Maheshwer B, Hong JY, Goldsmith AM, Bentley JK, Popova AP: Hyperoxic exposure of immature mice increases the inflammatory response to subsequent rhinovirus infection: Association with danger signals. J Immunol 2016;196:4692-4705.

52 Fenton TR, Premji SS, Al-Wassia H, Sauve RS: Higher versus lower protein intake in formula-fed low birth weight infants. Cochrane Database Syst Rev 2014:D3959.

53 Willems R, Krych L, Rybicki V, Jiang P, Sangild PT, Shen RL, Hensel KO, Wirth S, Postberg J, Jenke AC: Introducing enteral feeding induces intestinal subclinical inflammation and respective chromatin changes in preterm pigs. Epigenomics 2015;7:553-565. 